\title{
Lombaard's categorical invitation for minority dissent against 'suspicion': How real is the 'religious' in post-secular context?
}

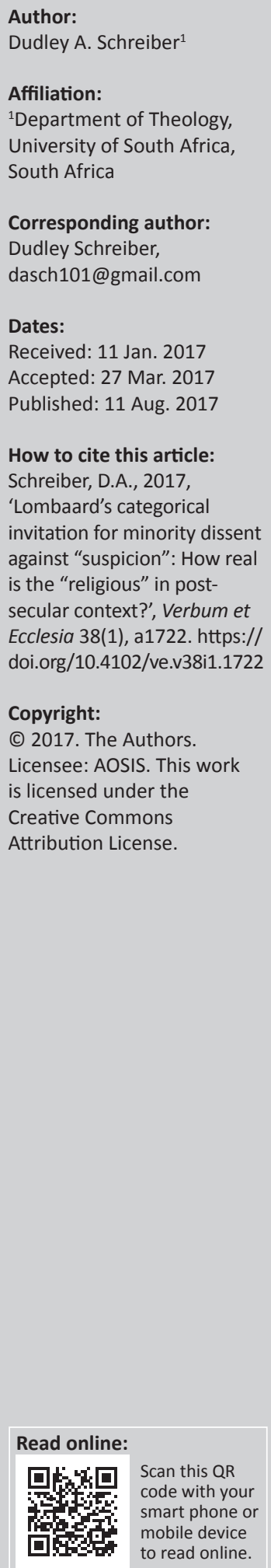

In the broader context of post-secularism and Lombaard's contributions, needful of philosophy, this minority report lights upon an analytic-post-secular crossover. Here, responding to Lombaard's categorical quest for the 'religious', philosophy serves to support greater realism in the discourse of the philosophy/sociology of religion so that we might better consider social, spiritual and philosophical capital. By small means, focusing on ontological, relational, democratic, psychological, social and analytic features of the humble category, it is suggested that an attitude of mitigated realism serves best in relief from suspicious theoretical pasts.

Intradisciplinary and/or interdisciplinary implications: This article attempts to demonstrate how post-secular categories like that of the 'religious' are enriched in post-analytic engagement with European philosophy and what this might require of theory.

... a universe comes into being when a space is severed or taken apart ... by tracing the way we represent such severance we begin to construct, with an accuracy and coverage that appears almost uncanny, the basic forms underlying linguistic, mathematical, physical and biological sciences, and begin to see how the familiar laws of our experience follow inexorably from the original act of severance. The act itself is remembered, even if unconsciously, in the first attempts to distinguish different things in the world where, in the first place the boundaries can be drawn anywhere we please. At this stage the universe cannot be distinguished from the way we act upon it, and the world may seem like shifting sand beneath our feet.

Although all forms, and thus all universes, are possible, and any particular form is mutable, it becomes evident that the laws relating such forms are the same in any universe. It is this sameness, the idea that we can find a reality which is independent of how the universe actually appears, that lends fascination ... and can show us something of the structure in which all creation holds, [it] is no new idea. (Brown 1969:1)

\section{Introduction: 'So what's in a category?' - A jocular point made serious}

Against normal academic practice, this article begins with a nubby joke, for the good of reason. It goes: 'What is the difference between a Pilot and God?' In reply it claims: 'God doesn't go around thinking He's [sic] a pilot'. Whilst teasing pilots may on occasion be funny, it is less easy to tease the second categorical Ultimatum in an extraordinary comparison! The humour rests in an artfully forced, instantly appreciated mistake (absurdum) and transgression of 'culturally cogent' (Lombaard 2016:2) assumptions, connections, norms and values, in a testy fashion about philosophical relatives and absolutes.

No doubt ridiculously attributed, the joke tricks us into confrontation with endangerment of sanity, sin against the category and the uproarious result of disobedience. The joke works seamlessly in more than some social circumstances for its versatile applicability to pilots, doctors and philosophical relativist 'pots', calling realist 'kettles ...'. Even in the jocular sense, the category is a weighty weapon of reasoning, culture, science and society. Asking, 'how weighty?', is the task of this small musing. Thus to begin, by noting that the fleet-footed appreciation of the joke (in some contexts) demonstrates how a number of ontological, epistemological, semantic and social relations are assumed and referenced in common reception.

Merely from commonality, it does not stretch imagination too far, for us to understand that categories are conceptual building blocks in culturally and analytically cogent chains of reason, definition sentences in science and so on. However, the proving thereof eludes capture. 


\section{Defining a category?}

Returning to the jocular experience, more than the clear semantic and other social links proposed by the joking, is a thin veiled assumption of realism, grounding our humorous and categorical effect. For our purposes, the joke instructs the quest for a broad working definition. We may read 'category' to mean:

- An assumption, type, concept or distinction which acts as a link in a set of conceptual (perhaps ontological, but certainly moral and scientific) relations, capable by their constitution of producing a sustainable chain of reason between definitions, theories, sciences and meta-theory, which they protect as quasi (minimal and falsifiable) arbiter, from numerous possible mistakes, contraventions, transgressions and confusions, endangering reason thus contextually understood.

\section{Realism and relativism in contemporary post-secular context}

In minority dissent from Van der Merwe's convinced relativist majority claim $(2016: 1)^{1}$, it is taken here that a principled realism has come into social theory (Bhaskar [1979] 1998:25-43; cf. Schreiber 2015:4), where 'the sense of problem has now shifted from ideas to reality itself' (Luhmann 2012:5). ${ }^{2}$ In this analysis, categories and classes of things arise in the world, which are differentiated in differentiation to other classes of things and they should never be confused or conflated ( Kant 2014:68-69)!

In the post-secular chain of reason and social theory, however, categorical placement is more slippery. Notably, therefore, there is common consensus that extra caution should be taken in appreciating a 'real' difference between absolute ontological 'apples', relative discursive 'science of apples' or relatively absolute 'Apple Brand'. In short, we need a clear view of real differences and relationships between ontology and epistemology. Alternatively, the results for methodology, clearer thinking and future construct of social categories could be disastrous (Kant 2014:1). Consequently, categorical investigations continue to be helpful and liberating (Bhaskar 1980; Bhaskar \& Hartwig 2012b) in elucidating Lombaard's religious quest and Van der Merwe's (2016) phenomenology. ${ }^{3}$

\section{A matter of differentiation, but in a context of relations}

Whilst appreciating that things basic to knowledge, like logical connections in discourse exist, they serve as categories (if at all) differently from others present in further degrees of

1.Though also to agree with Van der Merwe (2016:2) that 'Spirituality ... is understood differently from different perspectives'

2.Thus, Bhaskar (2002c:xxxvii) claims semiotic rearrangement is necessary: '... so that we have the immediate identity of being and meaning, reality becomes meaningful we have the displacement of meaning signification onto reality itself so that thine have the displacement of meaning, signification onto reality itself so that hermeneutically in a multiplicity of ways. The world becomes a meaningful text.'

3.Included here Van der Merwe's (2016) 'internal-external aspects' (p. 1), categories of 'lived experience' (p. 2), 'semantic networks' (p. 3), 'passive' and 'active' dynamics (p. 5), 'people' and 'things' (p. 6), 'discernment' (p. 12), 'concrete nature' (p. 13) and 'divine-human' (p. 16) conversation, respectively. relativity, for instance, in constructs like 'post-secularism', other 'patterns' (Bateson 1979:16, 17, 20, 22; Bateson \& Bateson 1987:8) and 'tropes' (De Man 1978:1, 17-19, 23-29). Nevertheless, realist assumptions include that categories exist ontologically; extend into epistemology; are practical in society, even when practically silly in semantic, creative and spontaneous play (for some, and there with limits controversially), because (wisely) not every distinction we make is a category; neither an epistemology nor is fetishable in any universe (Brown 1969:1). Consequently, in constructing a post-secular category or relational category (Bhaskar [1979] 1998:41; cf. Schreiber 2015:4) of use to Lombaard's 'religious', beyond naturalist constraint, ${ }^{4}$ a great deal of subtlety and ambiguity must be allowed to emerge into the social realism begged.

As indicated in this post-secular context, identifying the analytically available mistake or the offended rule of difference or misunderstood similarity in; ontology, concept or distinction, upholding the relationship between those oft doubted 'religious' and 'secular' social products (in postsecular and Lombaard 2014a, 2015d, 2016), is hard-pressed. Nevertheless, it is argued here that a relational analysis (that accommodates and hosts contradiction in transcendental relationships) from as far-a-field Systems theory, critical realism and post-analytic philosophy, serves well. Here, these sources are garnered to compose some 'minority report'. Value chains and chains of reason converge on the humble category, as Lombaard (2016:1) begs for his 'greater realism' (2015d:1), signalling a more balanced response to the extreme relativist and suspicious hegemony of previous learning.

Furthermore, it is argued that a philosophical attitude of relational realism is adequate for Lombaard's category, postsecular discourse generally, investigation of trends suiting secular versus religious debate in sociology of religion, and to some benefit of contemporary spirituality studies.

\section{Placement of the category in post-secular debate}

Where post-secular debate seems uncertain and suspicious about placing categorical status to social reality, one suspects it exceeds reasons of healthy scepticism, because it soon evidences a 'theoretically helpless embarrassment' (Luhmann 2012:12), 'irrealism' (Bhaskar 2002b:33, 2010:xxvi, 77) and 'suspicion' (Lombaard 2016:1). In diagnosis, the impasse

See Bhaskar's ([1979] 1998.2) quest for scientific 'unity' amidst the influence of 'scientism' and 'reductionism'. Also, Bhaskar ([1979]1998:3, 53, 80) has it: 'In particular it will be shown that ontological, epistemological and relational considerations all place limits on the possibility of naturalism (or rather, qualify the form it must take); and that these considerations all carry methodological import.'

5.Though establishing any such thing as a clear 'minority' in the historical progress within the philosophy of religion, is problematic (Long 2000:105) we 'can' as many have, look back on linguistic hegemony and fundamental approaches and in the sociology of religion (Dillon 2003) and see in them certain deficiencies, now becinning restoration of balance to epistemological attitudes. In part a minority, beginning restoration a minority, dissenting and accommodation, and, a generally perceived paucity of literature, it is nevertheless indicative of deeply spiritual res (n) is 'incomplete without acknowledging the larger engagement, Lombaard's exegetical and hermeneutic contributions have received (for instance with Farasan 2013) and numerous other respondents (Lombaard 2014b:477, ft.31). 
inhabiting secular-religious relations in social theory is largely the heir to classical realist and mentalist closure of categories (and facets of being) and ideology of dichotomous opposition. ${ }^{6}$ This, exacerbated by deconstructive closure on categories, in some similarity (and much dissimilarity, for some) has come into Systems debate on operational closure (Brown 1969; Bryant 2011:138-146; Luhmann 1990:7).

\section{Categorical closure in post-secular context}

Patently visible in post-secular closure 'plague' (Unger 1987:55), for instance, Beyers' (2014) categorical realism and social scepticism has it, not only the 'religious' (p. 3) but also Augustine's 'transcendent-immanent' (p. 4), Durkheim's 'sacred-profane' (p. 5), Berger's 'subjectiveobjective', 'appearance-disappearance' (p. 7) and Habermas' 'reason-faith' (p.10) are of a relative nature and therefore fail categorical status. So, whilst obviously apples and bricks plainly indicate different classes of ontology or categorical things, constructs, dualisms and opposing claims in postsecular debate do not.

This version of things not only acknowledges a 'difference' but also 'winters' it into categorical isolationism. In which case, post-secular discourse (its relational categories, distinctions and values) is left bereft of a chain of reason. In similar theoretical stalemate, we face the challenge that the religious term or distinction (God forbid a category?, for Chaves) exists in a discourse where no claim to universalised secularism or religionism (Chaves 1994:750) is known to succeed and is exactly (in paraphrase) 'Why secularism qua thesis, failed'. Whilst post-secularism is rightly no friend of rampant universalism, the lesson to be gleaned from secularism is that without a clear category, argument is limited in some way. Whilst that Agenda sought the marginalisation of religion, ${ }^{7}$ it found itself unable to offer a cohesive definition to isolate, nor marginalise.

Ultimately, Chaves believes the secularist argument failed to differentiate, universalise or cohere in any sense approaching a category. In pursuit of some structural realism, however, he immediately (not originally) adopts a power analysis. Even so, this but proves there can be no categorical winners except regionally and therefore

6.Bhaskar and Lawson (1998:3-15) and Archer (1998:ix-xxiv) comment on the human sciences during the 20th century that it evidenced a number dichotomies between 'hyper-naturalistic positivism and anti-naturalistic hermeneutics'; 'individualism and holism'; 'structure and agency'; and 'facts and values'. Also (Bhaskar [1979] and holism'; 'structure and agency'; and 'facts and values'. Also (Bhaskar 1979] 1998) 'reasons and causes (p. 87), 'mind and matter' (p. 97) and 'society and all dualism appears in Plato's Parmenides. There it appears as a 'body-soul' split that spawns the 'suspicious theory of two substances', which has under-structured science and methodology, politics, Church history and noted critically in Merton $(2003: 1,6,19-23)$. Although neat and appealing to the traditional, the orthodox Distinction, whether in philosophy as in religion, has certain complacent 'world without end' status. Nevertheless it does not escape the challenge that, upon these grounds alone, categorical judgment has little else to say but to the distinction between absolute or relative states of affairs and on the 'other', not much to say at all, thus suspending it into a dis-incarnate status.

7.In this regard, Roof $(2003: 138)$ makes the case for a clear distinction between 'Religion' and 'religious' noting that the latter is adjectival, as is not the more 'objective' former. The categorical and linguistic point made, however, the distinction is less clear in the social realm where adjectives attract pronouns, predicates and legal ontology, take up high offices and the like. Nevertheless, Roof clearly points to an ambiguity in widespread usage and appreciation of the category. uncertainly. Nevertheless, the relational dimension is obvious to the argument and to the post-secular extent (in caveat) that categorical identities and possible virtues are important for any ontological, ethical, existential, reflexive or spiritual transformation of society (Bhaskar 1993:223-366, 2012:127-129; cf. Schreiber 2015:3). ${ }^{8}$

\section{Categorical unity and ambiguity}

Rather, in post-secular minority reply the analytic and conceptual unity of (nevertheless faceted) being and knowing picks up a 'joined up' (Benedikter \& Molz 2012:29-74; Bhaskar 2010) resonance, in challenge to isolation hegemony. Therefore, this reply more than experimentally (among so many engagements and inter-sectional multi-disciplinary kisses that make paradigm ${ }^{9}$ ) proposes a cogent chain of reason at ontological, epistemological, ethical, semantic levels of interest and analytic necessity. Wherein contemporary discourse, a post-secular architecture of knowledge encroaches upon unity of science, being and ethics (Bateson 1979; Cat [2009] 2013; Kant 2014; Luhmann

8.For Bhaskar, social categories operate in a cube of relations states. These are firstly attitudes; secondly, attitudes to attitudes and further attitudes to those which mediate intra-psychic, trans-personal, institutional and cultural items and transactions in fundamental and unpredictable openness exhibiting transcendental possibility. Upon transcendental conditions, we are able to produce, reproduce and transform relations, contracts, constructs and categories (their 'reality' so taken). Merton's (2003) categorical argument is that, without a sense of category we can neither say 'I am' (p. 4), have a sense of natural unity (p. 3), nor the possibility of discerning a 'true' and 'false' self. Nevertheless, contemplative transformation ultimately requires a mature detachment from the personal category in order to overcome dualism (pp. 1, 6, 19-23, 39).

9.The 'relational value chain' (Segal 1991:83; cf. Schreiber 2015:3) or paradigm of post-secular significance breathes its inspiration from a multi-layered and disparate From historical perspective, a loss of spirituality came to characterise Western 'Production', heir to the marriage between technology, Protestant work ethic, liberalism and capitalism. Spiritual thirst in a soon to be post-Colonial World evidenced an East come West migration of non-Christian Spirituality. Centered on the principles of Eastern 'Non-duality' and Western 'non-separability' - relational themes soon to be taken-up in conceptual Sciences, though differently, in what (Du Toit 2016:1; Fox 1989:316-319) calls New Cosmology. The re-awakened resonances of 'unity and holism' in retrospect have become epistemological decentred 'wildfire'. In the Western sophistication of post-modern critiques targeting: Reductionism, mechanism, positivism, mentalism, dualism and dichotomy disenchantment, mechanism, positiss, mentalism, dualism and dichotomy, disenchantment, anthropocentrism, hegemony, patriarchy, extreme individualism, alienation and dichotomy, finds epistemological confluence and intimacy with a more complex Eastern wisdom and de-colonial promise. Among many religious and secula examples, these discourses indicate a (rough) movement seeking the liberation and protection of being, knowing and acting for the common good, on ideological and epistemological grounds. Meanwhile, cultural, traditional and ecological resonances beckon 'spiritual capital' in community and practicality. The post-secular analytic wing of study, therefore, confronts issues converging on the 'ontic', 'relational' and 'spiritual' turns of epistemological and social trend. None of these 'turns' are to extremes (affecting the secular and religious), but to a return of balance in mature post-modern 'return' to being, particularly highlighting the relationship between being and knowing. Some see this balance in notions of relativism, others in a mitigated ('critical') realism, all for good reason (Gerricke 2006:49, 52, 53-55) perhaps? Nevertheless hackles still rise, in debate. However, what becomes clear to some is that the grand literature of Relativism has no essential problem with Reality, nor its 'assumption', but with Representation and Interpretation namely Reception. nor its 'assumption', but with Representation and Interpretation, namely Reception. Immediately obvious for epistemological appreciation, Relativism is an approach applying directly to the epistemological realm; its rules of engagement should not impose on Reality nor Realism. To make such 'capture' is to commit 'Epistemic fallacy' (Audi 1998:324). However, it is precisely the realm of epistemology that must provide the post-secular analytic chain of reason capable of bridging dichotomy (if not duality) of mind-body problems (Bhaskar [1979] 1998:98; Van Gulick 2009:40-73; cf. Schreiber 2015:2; Hsieh 2003; Kant 2014). Furthermore, such analysis should deliver a self-conscious examination of philosophical conduct. To this point, the quest for categorical realism is of the moment. Notably, such analysis exhibits post-analytic trend for it includes possibilities of synthesis (Bevir 2001:4). To understand such might require adoption of a type of contradictory and incomplete sense of Holism (Jackson 2003:ix, 5-13; contra Bryant 2011), connecting the enduring and spiritual 'self' with a 'cosmological totality' (Van Ness 1996) ta renegotiated social realism. These conceptual links, or their lack, 'say something not only about the world but about me as a reasoned [ethical] person' (Audi 1998:2) and show the world but about me as a reasoned [ethical peron' (Audi 1998:2) and show here an ethical intention' in argument. The pertinent (minority) literature here indicates that a 'relational reading of the World and Knowledge practices seems to fit Kuhn's $(1962,1969)$ paradigmatic requirements. These in short are
categories proposing new relations; concepts and metaphors describing new relationships; analytic, critical, methodological and scientific 'traction', enough to relationships; analytic, critical, methodological and scientific 'traction', enough to
hold interest of a wide community, who buy into a techne and Zeitgeist of understanding. More so, Du Toit (2016:1-2) suggests for 'axial' context. 
2012:9; Merton 2003:310), it proceeds in the midst of 'ambiguous' (Van der Merwe 2016:1; Van Ness 1996:4) divergences and confluences in plurality or multi-complexity of social content (reason enough, to request some categorical surety?).

\section{The post-secular, post-analytic point}

The relativist point made (if we agree that relativism disputes only one thing, namely representation of reality), Bhaskar's ([1979] 1998) (critical) categorical realism asserts that assuming the reality of categories does not exclude differing types of necessity and endurance for those categories that exist in open societies, emerging nature and expanding cosmos. Presence of differing categorical types does not exclude a justifiable connection in chains of reason, nor constitute a 'mistake' (Bhaskar [1979] 1998:36-38; Kant 2014:69-79), but constitutes ontological emphasis. For this reason, Bhaskar proposes, ontological or not, social categories exhibit relative endurance and deserve the categorical appellation.

It is therefore clear to Smith and Medlin (1981) that the classical reading on categories is a poor servant of complex discourses and realities, because it is unable to 'handle all concepts' (p. 26), excludes 'disjunctive concepts' and 'unclear cases' (p. 29). This is of notable pertinence to post-secular debate 'unclear' as it is about whether one concept is a subset of another - as might indicate the case between secular, religious, mystical and spiritual categories. Whatever the case, in order to negotiate socially categorical being, we must challenge Western classical and mentalist assumptions that being and knowing are closed to each other They are firstly ontologically inseparable, and that they are conceptually distinct, does not challenge the point. The post-secular analytic wing is set to challenge theory itself.

\section{Lombaard's analytical realism}

As Lombaard (2016:3) comments on religion, in what is clearly a realistic assessment, it never really disappeared and is 'everywhere'. One is free to consider that when a social expression of being fails to disappear generally, any proposal that the theoretical representation of the category should dissolve is delusional. Especially so in the blatant visibility of religious bells, books, candles, practice and the lived experience of religious spirituality, $\mathrm{R} /$ religious communities, et cetera. We may participate or not, are present or not, but do not hold that on these grounds alone that the Religious is not. Absence is not always a clear categorical case. Consequently, many assumptions linking false chains of reason or hegemonic agendas require 'unmasking' (Beyers 2014:5).

\section{Eking categorical realism for a solution?}

By invoking the category, Lombaard (2016:1-2) obviously not only invites controversy (is thus 'mired') but also arguably entirety, body and soul, as part of the environment of the societal system'. evidences a slow embrace of realist assumptions, remote to his 2014a writing. ${ }^{11}$ Nevertheless, even if a confirmed postmodern mentalist there, Lombaard is not spared Tanney's (2007) analytical challenge. Unravelling and reconnecting assumptions in post-secular context neatly places a deserved emphasis on the relational aspects of a category.

\section{Post-secular relations, democracy and transcendence in Systems metaphor}

Upon these grounds, the Systems 'approach' recommends itself eloquently (if boastfully) for all social and epistemic systems (e.g. Bausch 2001; Bhaskar 2010; Bryant 2011; Jackson 2003; Luhmann 1990, 2012; Winder 2004). It readily participates in the discourse on social realism and takes note of subtleties formally under positivist taboo. Commenting on closure, Bryant (2011:149) notes, that whilst categorical closures of distinctive natural types exist, any form of distinction relies on the existence of at least two pre-existing relationships: The first, a democratic relationship with other systems and the second, a transcendent relationship with environment. Furthermore, Bryant (2011:158-159) has it that natural systems accommodate contradictory elements and much more so in social systems. Therefore, social differences are contextualised by a transcendent and democratic 'unity of entities'. Consequently 'dissenting' (Van Ness 1996:12) or contradictory entities are not irreconcilably alien nor to be excluded. It begs the suggestion that such a system of entities and categories is 'unified' in the emergence by a bigger category that is likely, over time.

Consequently, from naturalist metaphor (if permitted) and there with provisions (Bevir 2001:14; Bhaskar 2010:1-7; Bhaskar \& Lawson 1998:3, 6-7, 53, 82-83; Lombaard 2014a:1), neither apparent contradictions in reports, nor in social expressions, nor ambiguity, nor Lombaard's use of the (2016:3) 'or not' qualifier, is anomalous. Furthermore, nor do these deny categorical self-standing, for they exceed content. In possible challenge to Lombaard (2016), Bryant's democratic insistence in relational ontology bares consideration. Here, the secular and religious stand only in virtue of the democratic relationship between them as objects in discourse and messy, unpredictable society.

If we are to discern (one doubts) a 'suspicious' treatment of the secular in Lombaard (2016:2-4), Bryant's sub-categorical accommodation suggests that so-called 'secular' systems are inextricably, dualistically and dialectically involved with the 'religious', at many levels of agreement or dissent. The insight tempers unmitigated flights of epistemological or institutionalised autonomy or exclusivity. Though visible, traditional separation of secular or religious institutions does not taboo the more practical post-secular amalgamation of secular or religious transgression in their spaces nor the spaces of everyday life, not always a comforting thought.

11.Although an attitude of ethical realism is characteristic in Lombaard's (2014b:484) contribution. 


\section{The categorically painted lily}

In analytic consequence, when one category is chosen or elevated above the others of informative partnerships, it becomes a painted lily, or 'epistemic fallacy' (Audi 1998:324) to 'haunt' us (Luhmann 1990:25; cf. Bryant 2011:158; Slote 2013:210; cf. Schreiber 2015:7) with its implied partners in contradiction. Is Lombaard's 'religious' to haunt postsecularism and its capital with the 'secular'?

The corrective that Systems debate may claim, (keeping ontological priority in environment) is that what distinctions 'do', is to uphold a relationship by way of distinction. Real distinctions, therefore, uphold relational fabric in reality, theory, practice and philosophical discernment. Discursive (semantic) distinctions uphold the epistemological relations of discourse, even when ambiguously used. Discursive accommodation seems to suggest that the religious, mystical and spiritual furnish each other with their distinctions, however, so held. These terms may not displace each other at whim because they share in the discursive environment democratically and transcendentally. Lombaard, in his (2016:5) concluding 'humble-mumble', acknowledges the point.

\section{Categorical cultures}

Democracy and contradiction accepted, Audi (1998:249-279) and Rolston (1996:387-413) seem to suggest (with differences) that both secular and religious are interrelated 'cultures' and 'justified belief systems' because they have categories addressing necessity and deliver analytic propositions and in some cases a priori effect. These allow for synthetic reasoning in practical life, even though they may be ambiguous about ultimate differentials. As chains of reason or reasonable faith (if ever separable), these cultures are able to critique and deliver explanation of the other, precisely because they inform (reveal) each other, as categorical family. Consequently we may not, as Van Ness (1996:6) notes, expect pristine distinctions between 'salvific' and or 'flourishing' paradigms. Dualism in this sense, seems neither to hold theological nor philosophical water. (It would be a very bad Christian theology that conceived of salvation without its existential good and no ethical philosophy would pose none.) In fairness that accepted, this does not relieve much spirituality debate as to the precise relationship between mysticism, spirituality and religion nor the fact that all participants, academic and social are free to change their minds, as we do and must.

\section{Transcendence, a truly capital category}

A previously hinted 'reason' for our inability to settle religious as 'opposed' to secular priorities is because these are co-equal subcategories of something grander. Also these categories are extremely likely by Bryant's account (where hierarchies are minimal, if not flat), to accommodate elements or features belonging more classically in the other. Content it seems is not the reductive mark of categorical existence. The presence of secular religion makes the point, even when we do not know its sense. Perhaps this is why Lombaard's (2016:3) religious claim to be sometimes 'or not' is not necessarily a self-contradiction, nor a mistake. It is enough to indicate that relationships between categories and subcategories, questions of 'which are which?', are not easy to identify in post-secular social space.

Where we are mistaken in our prosecution for relief, Bhaskar suggests, is in paying too little categorical thought to the role of transcendence. Especially valuable on this matter, Bhaskar's contribution to the philosophical transactional analysis of transcendent acts, may assist in grounding Lombaard's (2016:3) 'capital'. Whilst it is true that capital directly provides a larger pragmatic social category to stand cogently as metaphor and analysis, it seems to beg the inclusive question: 'On what ground-state, virtue or trait such capital comes to have effect that is not only religious?' As Bhaskar (2002a:12, 2002c:iv; Bhaskar \& Hartwig 2012a, 2012b) has it, transcendence is a necessary condition for all transformations and mundane transactions and these are never exclusively religious.

However, what lies behind transcendental acts is a transcendental consciousness whose reflexive intervention is able to comment and formulate discourse on religious capital. In emphasis, thus 'whose' receptivity, empathic (Slote 2013; cf. Schreiber 2015) discernment and inner experience (Merton 2003:1-15) is open for business, religious or not. If we need an ontological category for an ontological argument, one might consider transcendence (Bhaskar 2002a:10, 178-179, 181, 2002b:ix-xi, 2002c:ix-xi, xxxii-xxxiv, 67-171; 2012:xiv-xxv, 145-148) and the role of virtue (Parker 2010:215-226). For this reason, one might find it less than satisfactory that the religious should count itself privileged to deny transcendent or spiritual capital (Lombaard 2015d, 2016:3) in the secular nor should it pompously 'appear' as the only conceptual respondent for categorical prosecution, in the grander debate.

\section{Transcendence and critical consequence}

Not without reason, we can on ontological grounds target Taylor's (2007:542-557; cf. Beyers 2014:5) untenable and preposterous claim that (even the point made) 'the immanent frame' (of secular reference) permits no 'immanent transcendence'. In response, many (Kee 2002:25, 27-28; Beyers 2014:8) find themselves dumbfounded and Bhaskar (as noted) would go to a refinement of war to demonstrate the fallacy.

Just as Lombaard's (2016:5) religious future 'is not without God',so Bhaskar's alternate text is not without 'transcendence', 'self-realization' in 'non-duality', 'freedom', 'creativity', 'love' and 'non-reductive discourses on God' (2002a:181-188; 2002b; Bhaskar \& Hartwig 2012a:145-164). For both thinkers conceivably, we are enveloped in reality (mystery), placed where 'immanent' and 'transcendent' categories must meet 'immanent' and 'transcendent' differentials, presumably meeting at some absolute (Bhaskar 2002c:xii, xxxii-xxxiv, 2012b:xiv, xxv)? 
It is perhaps in the context of transcendence as virtue that the transpersonal boundary (of a Categorical ' $\mathrm{I}$ ') is most meaningful. Whilst transcendence supports a primary categorical distinction to transgress, it is in the very act of transgression that confirms both the boundary and transition. Boundaries are perhaps better understood as 'transboundaries' or 'relations' that not only mediate categorical transaction, knowledge, production, reproduction and transformation (Bhaskar 2002a:12, 2002c:iv) in spirituality, mysticism and religion, but also secular reality.

\section{Presence and absence}

In society, Lombaard (2016:4) suggests, the religious may or may not be seen as such. Nevertheless, in reception of Lombaard, one believes (hermeneutically) the religious category is social capital or presumed cultural loss (Lombaard 2016:2) by its presence or absence, respectively. Plainly at many levels, our psychological, epistemological, social relations (proximity even in invisibility) and identification with categories are pertinent. Nevertheless, it is emphatically Lombaard's (2016:1) categorical point that even in absconditus these categories do not dissolve. The realist assumption remains on grounds of philosophical faith (at least). Bhaskar ([1979] 1998:28; Archer 1998:190) is well received for noting, therefore, that ontological categories in their social presence attract relational pronouns, predicates, roles and consequences. 'Society' is an unpredictable but not a totally unreliable expression of being and relationships.

An 'appearance' or 'moments' (Lombaard 2016:1) of social interaction may assist in unhaunting a conceptual ontology from static text or textual fallacy. By which text of being, existence informs us alethically (Bhaskar [1975] 2008:xi, 1993:101-102, 214; 2002a:202-203， 1993:101-102, 214), analytically and critically. Notwithstanding doubts about the momentariness, contingency, arbitrariness of relations so derived or formulated, Bryant and Luhmann (Bryant 2001:149) agree that 'flashes' of information do happen under both naturally and less socially 'unlikely' conditions. Thus, for multiple (even if a minority) analytical thinkers, a displacement of pure theory or pure construct vindicates a truer picture of life that is ontologically excessive of sociological trends (not that these are unimportant, in the realm of knowledge).

The momentary perspective on distinctions, however, casts doubt as to any weight they may hold beyond their epistemological value. For good ethical and democratic reasons, they should perhaps not carry more. However, we all know of instances whence a distinctive flash reveals 'a universe' (Brown 1969:1) or 'self-realization' (Bhaskar 2002c:xviii), 'ground-states' (Bhaskar 2002c:14), 'suchness' (Bhaskar 2002a:ix-xi), 'revelations' and 'satori' (Merton 2003:7, 9) or a lover, in the categorically undeniable reality of encounter. In short a mitigated social realism sense upholds the reality of such encounter. Notions about relatively secular or religious social states of affairs are not categorically uninformative. However, importantly for the category is the distinction between their structure and apparent events (Bhaskar 2010:3,9) - they are linked and minimally necessary to each other in processes. From the perspective of structural realism we may reflect that though distinct, categories serve as something approaching ground-states in consciousness, as passive virtues and traits that participate in a unified experience of ontology and epistemology, namely an interaction between capacity and social presence.

\section{Psycho-epistemic dimension of categories}

No doubt as many assume, there is an inevitable psychological relation to categories like institutions, policies, cultural items, movements and so on. The category is something on which, to make up our mind, in widely accepted commonality, vastly different from now discredited sociological 'apartheid ruled' (Mayson 2006:8) determinism. To this point, even though legislation has a social effect, we cannot attribute that effect without considering private motivations, pay-offs, liberation movements and the like. Neither sociological nor legal coercion (Unger 1987:49-54) is a clear case. They may be found religiously, and ethically objectionable, even when 'visibly' obeyed (Bhaskar [1979] 1998: 37-48; 1989:80; Slote 2013; cf. Schreiber 2015:5-6). In sub-verse, some ways of 'presenting' knowledge and self may significantly 'absent' majorly accepted norms, and sometimes by way of absconding.

Nevertheless, social and scientific transformation of categorical content is well known. Elderly categories change in theoretical content and newer ones emerge into the relational space between ontology and epistemology, begging some explanation of society and progress in science. ${ }^{12}$

If we take Lombaard's word that his religious quest somewhat exceeds the mentalism and deconstructionism of suspicion he targets, ultimately we are confronted with assumptions and analytic cost of social realism, replete with slippery, relational or relative states of affairs that nevertheless are 'taken' as real, because we common people experience them thus, in a post-secular, post-analytic, as opposed to a 'posttruth' age.

\section{The unity of transaction in common-sense}

In a common sense view, Lombaard's religious category is synthetic ('compound' for Van der Merwe 2016:3) and is placed in an inferred chain of reason and meaning which takes for granted, numerous capital assumptions of ontological weight, like causative agents, a category of transaction and (presuming) some sort of social agreement

12.Noting, for example, that Einstein takes the Newtonian concept of Mass, to leave it forever changed in a new set of categorical relations and a veritable scientific 'revolution', Bhaskar has it (2010:3) that Einstein's adoption is 'unilaterally ' version is 'taxonomically 'moreduch explanation) 'causally irreducible. Over time, categories are unstable and are falsifiable, but reorganisation of content, may bring a concept into disuse but never denies the overall structural value of categories. 
(dare one say Constitution) to be transacted. May we presume like Tanney ([2007] 2015:1) that the causal power of the mental and ontological facets of being joins in some unity in-and-of social transaction, agreement, possible contradiction, receptivity and transcendence?

Here as Audi (1998) notes, (in possible understatement) even when not directly self-evident, categories are legitimately 'indirectly' to be inferred for the sake of a 'commonsense

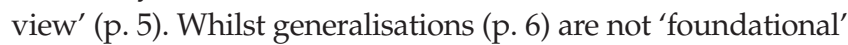
(p. 111), they are a 'way' of grounding (p. 6), enough to assume analytic 'truth' (p. 111) linking 'causal justification' and 'epistemological grounding'. Consequently, categories continue instrumental casting in analytic memory (as learning wheels of a more dynamic process of epistemic mobility) and have 'a certain minimal strength' (p. 317). Importantly, such information 'is a structure ... anchored both internally and externally to the world' (p. 324), in agreement with Brown. Thus, any quest for contemporary categorical realism depends on ontological and epistemological balance to say the least of unity or reason, religious or not.

\section{Danger, danger ...?}

As South Africans know of social categories when imposed, they change relations - intellectual, social and economic to put people at torturous disadvantage and at other times or places, not. Nevertheless, the instrumental imposition of social categories based on identity politics (Unger 1987:50), challenges natural intimacies and is thus, far from innocent (Klaasen 2016:1-3). So deployed, by a chain of 'reason', categories are alternately the source of atrocity, cruel jokes, permissive playfulness, silly rhymes, alternative marketing, terrorism and so on. There is a 'line'. Such categorical imposition is indeed for learning in a range of attitudes, not for imposing mechanistically, unless playfully, ethically, lovingly and only sometimes legislatively. Whilst it is obvious that all these ingredients of social and political life, mediate categorical understanding, continuously tests our Constitutional chain of reason and so on, it is the realist point that. Categories take their reference from and contribute to the text of cultural intelligence or lack. Including variations encountered, subverted, nevertheless read, felt, tasted and experienced, beyond one textual hegemony, into life and ontological reality.

\section{A conclusion of parts}

Penultimately, one may pose the question: Where would existence and culture 'be' sans an appreciation of categories; practically, ontologically, valuatively, politically, or placed humorously by sleight of tongue, yet ubiquitously understood as imposing a valid social warning? How carefully we place categories is the critical, philosophical and moral point of interest that binds concern for philosophy, post-secularism and liberation! Refusing them is something of a lesser option, unless all conversation, love, knowledge, humour and postsecular discourse is reducible to madness, deficit or incapacity.

\section{So what is in the unity of a category?}

If the above suggestion is an uproarious notion, it speaks of an in-appropriation of division, misplaced unity and confusion of categorical states fundamental to ethical, social and scientific reasoning. We as reasonable people may be incomplete but are not madness, deficit or incapacitated. Much that has bugged previous thinking finds itself in contradiction of post-secular, religious, analytic, critical and ethical cogency and a more adequate reading of the world, as we love it, namely categorically and irrevocably. Clearly, categories are rules of ontological and epistemological excellence, discerned in the passive and active aspects of 'lived experience' (Van der Merwe 2016:2) capable of negotiating an adequate fullness of virtue (something tight and elastic). Contemplatives, mystics and meta-analysts agree (albeit by a proud minority) that our categorical quest is important, should exhibit a playful unity between epistemology and ontology, so that we might encounter our own integration and presence in a relational context and often divided world.

No doubt many cultural approaches seek to explain or extrapolate a chain of reason that connects one concrete individual with the world. This actuality is a testament of a spiritually real thirst for integration, in slow embrace of some incompletely perceived 'totality'. The categorical quest may provide an impoverished sense of structural connectivity and prove a process. Yet mundanely, intra-psychically, existentially, intentionally, transcendentally, trans-personally and socially, by secular or religious means, we navigate on highly elastic relations to less elastic categorical poles. These are in no sense remote to our existence as concrete singularities in public, institutional, cultural and scientific production, reproduction and transformation.

\section{Concluding implications}

Quite rightly, in response to a history of 'Whitley' and wrongfully imposed suspicion, the politics of Identity under-structures, occasionally over-structures conversational, ideological and categorical background to reason. The categorical and historical context in which reason is structured and highlighted in aspects of contemporary South African discourse and consciousness, makes evident their ontologically cast seriousness. So too it indicates the seriousness with which to examine the virtue of social elasticity and resilience by placing a category needfully, democratically and gently. Epistemological placement of 'the category', though useful in a 'bendy' way, begs transcendence into ontology and receptivity of being. On these grounds perhaps the category is naturally placed as a masterful servant of reason and query. This minor philosophical contemplation of small things, points us to a way of undoing a false split in former debate. At what first appears as an unclear epistemological case or assumption, soon reveals itself very clearly in the negotiated reality of society. Thus categories, though due their social minimalism in social presentation especially, are precisely that due given by their ontological and social reality. The option for a softened social 
realism becomes reasonable for a society in (transcendental) search for itself.

Freedom from a foreign way of imposing and learning categories no doubt is a virtue, as is their relative learning, recognition and therefore their value, for others. Reducing 'foreignness' to 'falseness', Merton suggests, beckons conversion (a process of inner learning) and Bhaskar, a spiritual turn. The argument here categorically participates in a valid chain of reason that includes faith, trust, transaction, and transcendence in a way that challenges the primacy of religion over 'other' alternatives. All such ways, traditional or not, of; transcendental, political, social and personal experience are not independent, not separable and are always negotiated in the accommodation of something foreign (present or absent). It may be said that a 'minority' sense of realism, reclaims; agency, encounter, challenge, powers of re-interpretation and a truer balance of reason, for the majority. In 'pause' for that reason, the 'religious' category should be well considered if never to be prescribed, perhaps.

\section{Acknowledgements Competing interests}

The author declares that he has no financial or personal relationships that may have inappropriately influenced him in writing this article.

\section{References}

Archer, M., 1998, 'General introduction', in M. Archer, R. Bhaskar, A. Collier, T. Lawson \& A. Norrie (eds.), Critical realism: Essential readings, pp. ix-xxiv, Routledge, London.

Audi, R., 1998, Epistemology: A contemporary introduction to the theory of knowledge, Routledge, London.

Bateson, G., 1979, Mind and nature: A necessary unity, Fontana, London.

Bateson, G. \& Bateson, M., 1987, Angels fear: An investigation into the nature and meaning of the sacred, Rider, London.

Bausch, K.C., 2001, The emerging consensus in social systems theory, Kluwer, New York.

Benedikter, R. \& Molz, M., 2012, 'The rise of neo-integrative worldviews: Towards a rational spirituality for the coming planetary civilization?', in M. Hartwig \& J. Morgan (eds.), Critical realism and spirituality, pp. 29-74, Routledge, Oxon.

Benton, T., 2001, 'Why are sociologists naturephobes?', in J. López \& G. Potter (eds.), After postmodernism: An introduction to critical realism, pp. 133-145, Athlone Press, London.

Bevir, M., 2001, 'Taking Holism seriously: A reply to critics', in Philosophy books, vol. 42, pp. 187-195, University of California, Berkley, viewed 24 April 2016, from http://escholarship.org/uc/item/729394vw

Beyers, J., 2014, 'The church and the secular: The effect of the post-secular on Christianity', HTS Theological Studies 70(1), Art.\# 2605. https://doi.org/10.4102/ hts.v70i12605

Bhaskar, R., [1975] 2008, A realist theory of science, Routledge, London.

Bhaskar, R., [1979] 1998, The possibility of naturalism: A philosophical critique of contemporary human sciences, Routledge, London.

Bhaskar, R., 1980, 'Scientific explanation and human emancipation', Radical Philosophy $26,16-28$.

Bhaskar, R., 1993, Dialectic: The pulse of freedom, Routledge, New York.

Bhaskar, R., 2000, From east to west, Routledge, New York.

Bhaskar, R., 2002a, Reflections on meta-reality: Transcendence, emancipation, and everyday life, Sage, London.

Bhaskar, R., 2002b, The philosophy of meta-reality. Volume 1, meta-reality: Creativity, love and freedom, Sage, London.

Bhaskar, R., 2002c, 'The philosophy of meta-reality, part 2: Agency, perfectibility, novelty. Interview by Mervyn Hartwig', Journal of Critical Realism 1(1), 67-93.
Bhaskar, R., 2010, 'Context of interdisciplinarity', in R. Bhaskar, C. Frank, K. Hoyer, P. Naess \& J. Parker (eds.), Interdisciplinarity and climate change: Transforming knowledge and practice for our global future, pp. 1-23, Routledge, New York.

Bhaskar, R. \& Hartwig, M., 2012a, 'Beyond East and West', in M. Hartwig \& J. Morgan (eds.), Critical realism and spirituality, pp. 187-202, Routledge, Oxon.

Bhaskar, R. \& Hartwig, M., 2012b, '(Re-)contextualizing meta-reality', in M. Hartwig \& J. Morgan (eds.), Critical realism and spirituality, pp. 215-216, Routledge, Oxon.

Bhaskar, R. \& Lawson, T., 1998, 'Introduction', in M. Archer, R. Bhaskar, A. Collier, T. Lawson \& A. Norrie (eds.), Critical realism: Essential readings, pp. 3-15, Routledge, London.

Brown, G.S., 1969, Laws of form, George Allen \& Unwin, London.

Bryant, L., 2011, The democracy of objects, Open Humanities Press, Ann Arbor, MI.

Cat, J., [2009] 2013, 'The unity of science', in E.N. Zalta (ed.), Stanford encyclopedia of philosophy, viewed 3 June 2016, from http://plato.stanford.edu/entries/ scientificunity

Chaves, M., 1994, 'Secularization as declining religious authority', Social Forces 72(3), 749-774.

De Man, P., 1978, 'The epistemology of metaphor', Critical Inquiry 5(1) Special issue on metaphor, Autumn, 13-30.

Dillon, M. (ed.), 2003, Handbook of the sociology of religion, Cambridge University Press, Cambridge.

Du Toit, C.W., 2016, 'Human uniqueness on the brink of a new axial age: From separation to reintegration of humans and nature', HTS Theological Studies 72(4), a3487. https://doi.org/10.4102/hts.v72i4.3487

Fox, M., 1989, The coming of the cosmic Christ: The healing of mother earth and the birth of a global renaissance, Harper Collins, San Francisco, CA.

Gericke, J., 2006, 'Realism and non-realism', Old Testament Essays 19(1), 47-57.

Heelas, P., 2002, 'Implicit religion: Ineffability', in É. Bailey (ed.), The secular quest for meaning in life, pp. 215-232, Edwin Mellen Press, New York.

Hsieh, D., 2003, 'Analytics on mind: An objectivist survey of analytic philosophy of mind and criticism of the body mind dualism', viewed 02 January 2016, from http://www.psu.edu/

Jackson, M.C., 2003, Creative Holism for business managers, Wiley, Chichester

Kant, S.L., 2014, 'The distinction and relationship between ontology and epistemology. Does it matter?', in V. Simral (ed.), Politikon: IAPSS Political Science Journal, 24 September, pp. 68-85, International Association for Political Science Students, Nijmegen.

Kee, A., 2002, 'The experience of transcendence in contemporary culture', in É. Bailey (ed.), The secular quest for meaning in life, pp. 121-136, Edwin Mellen Press, New York.

Klaasen, J., 2016, 'Identity, race and faith: The role of faith in post-Apartheid South Africa', HTS Theological Studies 72(2), a3861. https://doi.org/10.4102/hts. v72i 2.3861

Kuhn, T., [1962] 1969, The structure of scientific revolutions, Chicago University Press, Chicago, IL.

Lombaard, C., 2014b, 'Mysticism and understanding: Murmurs of meaning (fulness) Unheard silences of Psalm1', Old Testament Essays 27(2), 472-400.

Lombaard, C., 2015d, “'Deus ex Machina," religious texts, spiritual capital and inequalities: In continuation of a current debate (a response to colleague Farisani)', Verbum et Ecclesia 36(1), Art.\# 1378. https://doi.org/10.4102/ve. v36i.1378

Lombaard, C.J.S., 2014a, “'And never the twain shall meet?" Post-secularism as newly unfolding religio-cultural phase and Wisdom in ancient Israelite phenomenon. Spiritualities and implications compared and contrasted', paper prepared for the 4th Global Conference on Spirituality in the 21st Century, Angelo Hotel, Prague, Czech Republic, 18-20 March.

Lombaard, C.J.S., 2016, 'Sensing a "Second Coming": An overview of new concepts in Sociology, Philosophy, Law and Theology on the re-emerging religious in private and public life', Verbum et Ecclesia 37(11), a1488. https://doi.org/10.4102/ve. v37:1.1488

Long, E.T., 2000, Twentieth century western philosophy of religion: 1900-2000, Kluwer, London.

Luhmann, N., 1990, Essays on self-reference, Columbia University Press, New York.

Luhmann, N., 2012, Theory of society, vol. I, transl. R. Barret, Stanford University Press, Stanford, CA.

Mayson, C., 2006, 'Into the world come of age', in C. du Toit \& C. Mayson (eds.), Secular spirituality as contextual critique of religion, pp. 1-23, Research Institute for Theology and Religion, Unisa, Pretoria.

Merton, T., 2003, The inner experience: Notes on contemplation, Harper Collins, San Francisco, CA.

Parker, J., 2010, 'Towards a dialectic of knowledge and care in the global system', in R. Bhaskar, C. Frank, K. Hoyer, P. Naess \& J. Parker (eds.), Interdisciplinarity and climate change: Transforming knowledge and practice for our global future, $\mathrm{pp}$. 215-226, Routledge, New York.

Rolston, H., 1996, 'Scientific enquiry', in H.P. Van Ness (ed.), Spirituality and the secular Quest, pp. 387-413, Kluwer, London.

Roof, W.C., 2003, 'Religion and spirituality: Toward an integrated analysis', in M. Dillon (ed.), Handbook of the sociology of religion, pp. 137-150, Cambridge Universit Press, Cambridge.

Schreiber, D., 2015, 'Transformation, agency and virtue from three contemporary philosophical inspirations: Bhaskar, Segal and Slote', HTS Theological Studies 71(1), 1-10. https://doi.org/10.4102/hts.v71i1.2974 
Schreiber, D.A., 2013, 'Joined-up knowledge for a joined-up world. Critical realism, philosophy of metareality and the emancipation in/of anthropological spirituality:
An exploration of confluences', MTh dissertation, University of South Africa, An explorat

Segal, J., 1991, Agency and alienation: A theory of human presence, Rowan \& Littlefield, New York.

Smith, E.E., \& Medlin, D.L., 1981, Categories and concepts, Harvard University Press, London.

Slote, M., 2013, From enlightenment to receptivity: Rethinking our values, Oxford University Press, Oxford.

Tanney, J., [2007] 2015, 'Ryle', in N. Zalta (ed.), Stanford encyclopedia of philosophy, viewed 10 April 2016, from http://plato.stanford.edu/entries/ryle

Taylor, C., 2007, A secular age, Harvard University Press, Cambridge, MA.
Unger, R.M., 1987, Social theory: Its situation and its task - A critical introduction to politics, a work in constructive social theory, Press Syndicate of the University of Cambridge, Cambridge.

Van der Merwe, D., 2016, 'A phenomenology of Christian spirituality: In conversation with God', paper presented at the University of South Africa, 23 February 2016, Publication forthcoming.

Van Gulick, R., 2009, 'Reduction, emergence, and the mind/body problem: A philosophic overview', in N. Murphy \& W. Stoeger (eds.), Evolution \& emergence: Systems, organisms, persons, pp. 40-73, Oxford University Press, Oxford.

Van Ness, H.P., 1996, 'Introduction', in H.P. Van Ness (ed.), Spirituality and the secular quest, Kluwer, London.

Winder, N., 2004, 'Towards a theory of knowledge systems for integrative socionatural science', Human Ecology Review 11(2), 118-132, viewed 14 June 2015 from http://www.apjh.humanecologyreview.org 